\title{
Short-term outcomes after minimally invasive versus open pancreaticoduodenectomy in elderly patients: a propensity score-matched analysis
}

Shih-Min Yin", Yueh-Wei Liu*, Yu-Yin Liu, Chee-Chien Yong, Chih-Chi Wang, Wei-Feng Li and Cheng-Hsi Yeh

\begin{abstract}
Background: To date, the evidence on the safety and benefits of minimally invasive pancreatoduodenectomy (MIPD) in elderly patients is still controversy. This study aim to compare the risk and benefit between MIPD and open pancreatoduodenectomy (OPD) in elderly patients.

Methods: From 2016 to 2020, we retrospective enrolled 26 patients underwent MIPD and other 119 patients underwent OPD. We firstly compared the baseline characteristics, 90-day mortality and short-term surgical outcomes of MIPD and OPD. Propensity score matching was applied for old age patient ( $\geq 65$-year-old vs. $<65$-year-old) for detail safety and feasibility analysis.

Results: Patients received MIPD is significantly older, had poor performance status, less lymph node harvest, longer operation time, less postoperative hospital stay (POHS) and earlier drain removal. After 1:2 propensity score matching analysis, elderly patients in MIPD group had significantly poor performance status $(P=0.042)$ compared to OPD group. Patients receiving MIPD had significantly shorter POHS (18 vs. 25 days, $P=0.028$ ), earlier drain removal (16 vs. 21 days, $P=0.012)$ and smaller delay gastric empty rate $(5.9$ vs. $32.4 \% P=0.036)$. There was no 90 -day mortality ( $0 \%$ vs. $11.8 \%, P=0.186)$ and pulmonary complications ( $0 \%$ vs. $17.6 \%, P=0.075)$ in MIPD group, and the major complication rate is comparable to OPD group ( $17.6 \%$ vs. $29.4 \%, P=0.290)$.

Conclusion: For elderly patients, MIPD is a feasible and safe option even in patients with inferior preoperative performance status. MIPD might also provide potential advantage for elderly patients in minimizing pulmonary complication and overall mortality over OPD.
\end{abstract}

Keywords: Minimally invasive pancreatoduodenectomy, Elderly patients, Short-term postoperative outcomes, Propensity score-matched analysis

\section{Background}

According to the latest Global Health Observatory data of the World Health Organization (2016), the average life expectancy of the global population is 72 years. Despite

*Correspondence: dreamhunteryin@hotmail.com; anthony0612@me.com Division of General Surgery, Department of Surgery, Kaohsiung Chang Gung Memorial Hospital and Chang Gung University College of Medicine, No.123, DAPI Rd. Niaosng Dist, Kaohsiung City 83301, Taiwan reduction in mortality rates due to improved surgical techniques, elderly patients are still considered a highrisk population for major abdominal surgery $[1,2]$. On the other hand, since the increase in life expectancy may be associated with the risk of developing periampullary cancer [3-5], it is reasonable to expect higher number of elderly patients with resectable periampullary cancer.

Pancreaticoduodenectomy (PD) is considered the only potentially curative surgical procedure in patients with 
periampullary malignancy. However, it is also one of the most challenging and complex surgeries due to requirement of numerous reconstructions and the presence of anatomical variations. Although mortality rates for pancreatic surgery in high volume centers can be much lower (approximately 3\%) [6], several studies still reported relatively high mortality (up to 6\%) and morbidity (ranging approximately $40-50 \%[7,8]$, including common complications such as pancreatic fistulas, post-pancreatectomy bleeding, anastomotic leakage and delayed gastric emptying. Therefore, performing PD in elderly patients is challenging and controversial. Although several studies have reported on the safety and feasibility of open pancreaticoduodenectomy (OPD) in elderly patients without significant increase in the mortality and morbidity $[9,10]$, the risk for major complication and prolong postoperative recovery is still remain great concern. Recent studies have also reported more number of major post-pancreatectomy complications [11], and significantly higher 30 -day and 60-day mortality in elderly patients $[12,13]$.

Minimally invasive surgery (MIS) has been accepted for the treatment of gastrointestinal and colorectal malignancies owing to its safety and feasibility, even in elderly patients [14, 15]. However, minimally invasive pancreaticoduodenectomy (MIPD), including laparoscopic pancreaticoduodenectomy (LPD) and robotic pancreaticoduodenectomy (RPD), are not routinely performed due to technique sensitivity and safety considerations involved. Although several meta-analysis and case series have reported the safety and feasibility of MIPD compared to OPD [8, 16-18], evidence from randomized controlled trials remain controversial $[19,20]$. In particular, there is limited evidence regarding safety and benefits of MIPD compared to OPD in elderly patients.

The aim of this study was to compare the short-term postoperative outcomes of MIPD and OPD between elderly ( $\geq 65$-years-old) and non-elderly ( $<65$-years-old) patients. By using propensity score-matching (PSM) analysis, we aimed to precisely evaluate the safety and feasibility of these procedures in elderly patients.

\section{Methods}

\section{Patient selection and choice of surgical procedure}

In the present study, we retrospectively collected clinical data of patients who underwent PD for periampullary tumors between November 2016 and May 2020. The study was approved by the Institutional Review Board (IRB), under authorization No. 202000247B0, and was conducted at Kaohsiung Chang Gang Memorial Hospital, Kaohsiung, Taiwan. The patients were divided into two groups based on the surgical approach used. Age cut-off of 65 years was considered in the definition of "Elderly patients," which was compatible with previous studies on pancreatic surgery in elderly patients [21,22]. Patient less than 18-year-old, PD was performed due to colon cancer direct invasion, and patients converted to total pancreatectomy or hepatopancreatectomy were excluded. The study flow diagram was shown in Fig. 1

The patients made the choice of minimal invasive surgery (including LPD and RPD) or traditional open approach after their attending doctors carefully explained the surgical details, advantages and disadvantages, and the possible cost difference between the different approaches. We did not consider patients with previous laparotomic surgery as the contraindication for MIPD candidates. However, for patient underwent neoadjuvant chemotherapy and patients with borderline resectable pancreatic cancer, the traditional open approach would be suggest to the patients. The same group of surgeons performed the surgery, and patients received the standard postoperative care and surveillance protocol.

\section{Surgical procedures}

Both LPD and RPD were performed by the hybrid method. The laparoscopic procedure was started with three $12 \mathrm{~mm}$ ports and two $5 \mathrm{~mm}$ ports. The robotic procedure was started with three robotic $8 \mathrm{~mm}$ ports, one $12 \mathrm{~mm}$ camera port, and one $12 \mathrm{~mm}$ assistant port. The dissection was done with the "Artery first" approach from left to right, bottom to top. Standard pancreatoduodenectomy (classical Whipple procedure) was performed. In cases with malignancy, extended lymph node dissection and level II total mesopancreas excision was done. After complete resection of the specimen, hepatojejunostomy and retrocolic gastrojejunostomy were performed by the minimally invasive method. A $5-7 \mathrm{~cm}$ upper midline incision was made to remove the specimen and perform pancreaticojejunostomy by hand-sewing, duct to mucosa method. If severe adhesion or tumor invasion of a major vessel was encountered, vascular resection and reconstruction was also performed by the hybrid method from the upper midline wound at the end of resection. All OPD surgeries were performed by the classical Whipple procedure.

\section{Surgical and postoperative outcomes}

The overall morbidity and in-hospital mortality were considered the primary outcome measures. Preoperative data of the Eastern Cooperative Oncology Group (ECOG) Scale of Performance Status, American Society of Anesthesiologists (ASA) physical status classification, and other comorbidities were compared between MIPD and OPD groups. Charlson comorbidity index (CCI) was also applied for comorbidity evaluation [23]. Other surgical data including operative time, intra-operative estimated blood loss (EBL), and conversion rate was 


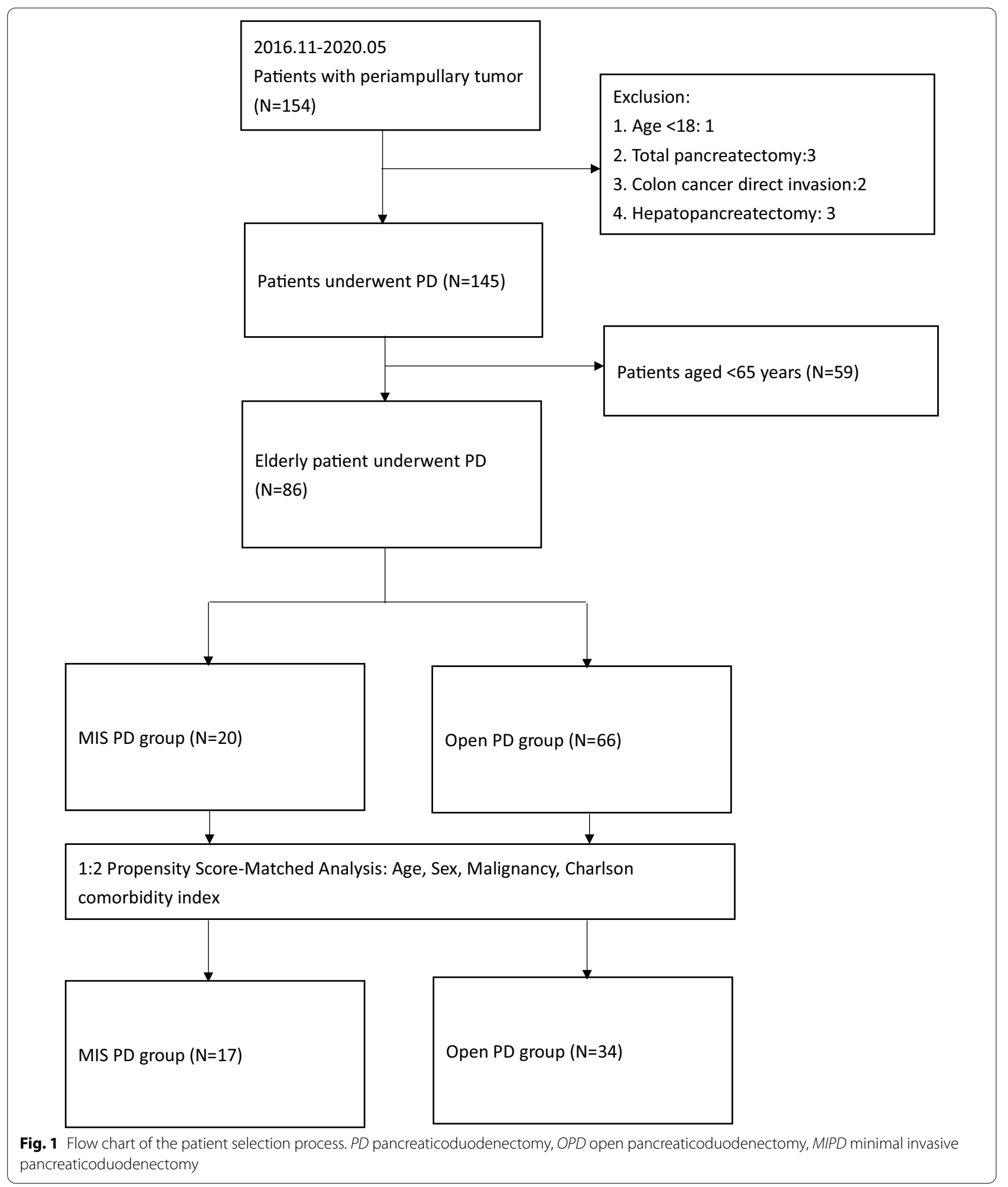

recorded. Postoperative recovery data including postoperative hospital stay (POHS), intensive care unit (ICU) stay, time of initiation of diet, ambulation, and complete drain removal was also compared between the groups. Recorded post-operative complications included postoperative pancreatic fistula (POPF), delayed gastric 
emptying (DGE), post-pancreatectomy hemorrhage $(\mathrm{PPH})$, pulmonary complication and intraabdominal infection (IAI) among other major complications. POPF, DGE, and PPH were defined and classified by the International Study Group of Pancreatic Surgery (ISGPS) [2426], and only grade B and grade C POPF were recorded. A major complication was considered as one with a score $\geq 3$ based on Clavien-Dindo classification [27]. Mortality was defined as death before discharge of the patient or within 90 days after surgery.

\section{Statistical analyses}

Statistical analyses were performed using IBM SPSS Statistics for Windows, version 20.0 (IBM Corp., Armonk, NY, USA) and NCSS 10 software (NCSS Statistical Software, Kaysville, UT, USA). Two-sided Fisher's exact or Pearson chi-square tests were used to compare categorical data. The normally distributed continuous and nonnormally distributed data were analyzed with unpaired Student's t- and Mann-Whitney U-tests, respectively, and presented as mean \pm standard deviation or median with interquartile rage (IQR).

To minimize the potential confounding effects of the compared patient populations due to non-randomized assignment, a 1:2 PSM study group (MIS vs. Open surgery) was created using the Greedy method with a 0.2 caliper width using NCSS 10 software. The PSM analysis was performed using a logistic regression model with the following covariates: Age, sex, malignancy status, and CCI. After adjusting for these confounding factors, binary logistic regression analysis was used to evaluate the effect of minimally invasive and open surgery on postoperative recovery. Statistical significance was set at a P-value of $<0.05$ for each analysis.

\section{Results}

\section{Baseline characteristics and clinicopathological variables} of patients

We totally enrolled 154 patients with periampullary tumor in this retrospective series. After excluded 1 patient less than 18-year-old, 2 patients with colon cancer direct invasion, 3 patients converted to total pancreatectomy and 3 patient received hepatopancreatectomy, total 145 patients were eligible for our further analysis (Fig. 1). Out of the total 145 patients included in this retrospective series, 119 patients were in the OPD group, and 26 patients were in the MIPD group (six patients underwent RPD and 20 patients underwent LPD). Baseline characteristics and clinicopathological outcomes are presented in Table 1. The mean age of patients in MIPD group was higher than those in the OPD group $(71.03 \pm 8.8$ and $64.40 \pm 11.7$ years, $\mathrm{P}=0.008)$. Patients in the MIPD group also had poor performance status $(\mathrm{P}=0.036)$ and less number of harvested lymph nodes $(14.23 \pm 8.04$ vs. $19.83 \pm 9.71, \mathrm{P}=0.04)$. Similar male-to-female ratio, ASA, tumor size, previous abdominal surgery, rate of preoperative biliary drainage, and underlying comorbidity was found between two groups. Details of pathologic outcomes are also listed in Table 1.

\section{Short-term postoperative outcomes of patients}

Table 2 shows surgical data and short-term postoperative outcomes of the two groups. Patients in the MIPD group had significantly longer surgical time (540 vs. $462 \mathrm{~min}$, $\mathrm{P}=0.011$ ), shorter POHS (18 vs. 24 days, $\mathrm{P}=0.001$ ), and earlier complete drain removal (16 days vs. 22 days, $\mathrm{P}<0.001$ ). The overall conversion rate in the MIPD group was $11.1 \%$. There was no significant difference in EBL, postoperative ICU stay, time of initiation of oral diet and ambulation, total parenteral nutrition (TPN) dependence, and 30-days re-admission rate. Occurrence of surgical mortality, major complications and rates of POPF, DGE, and PPF were similar between OPD and MIPD groups.

\section{Overall comparison between MIPD and OPD in elderly patients}

The baseline characteristics and short-term postoperative outcomes in elderly patients are presented in Tables 3 and 4. In this cohort, 20 elderly patients underwent MIPD while 66 underwent OPD. Significantly shorter POHS (18 days vs. 24 days, $\mathrm{P}=0.014$ ) and earlier complete drain removal (16 days vs. 22 days, $\mathrm{P}=0.004$ ) was observed in elderly patients who underwent MIPD. The occurrence of DGE was significantly less in MIPD group ( $10 \%$ vs. $33 \%$, $\mathrm{P}=0.042$ ). There was no significant difference in parameters of sex, ASA score, EBL, harvested lymph nodes, and other short-term postoperative outcomes. Similar rate of major complications, POPF and PPF was found between two groups. No death was reported in elderly patients who underwent MIPD; however, the mortality rate in the OPD group was $9.1 \%(\mathrm{P}=0.193)$.

\section{Propensity score-matched comparison of elderly patients who underwent MIPD and OPD}

A one-to-two PSM analysis was applied (17 patients in the MIPD group and 34 patients in the OPD group), adjusted for sex, age, CCI and pathologies, as shown in Table 3. Although poor preoperative performance status was observed in patients underwent MIPD $(\mathrm{P}=0.042)$, the MIPD group still presented significantly shorter POHS (18 days vs. 25 days, $\mathrm{P}=0.028$ ), earlier complete drain removal (16 days vs. 21 days, $\mathrm{P}=0.012$ ) and less rate of $\mathrm{DGE}(5.9 \%$ vs. $34.2 \%, \mathrm{P}=0.036)$ than the $\mathrm{OPD}$ group. There were no significant differences in surgical time, EBL, initiation of oral diet and ambulation, 
Table 1 Overall baseline characteristics and pathological outcomes

\begin{tabular}{|c|c|c|c|}
\hline Variables & MIPD $(\mathrm{N}=26)$ & OPD $(N=119)$ & P-value \\
\hline Age (years) & $71.03 \pm 8.8$ & $64.40 \pm 11.70$ & 0.008 \\
\hline Male (Male) & $16(61.5 \%)$ & 70 (58.8\%) & 0.490 \\
\hline ASA (n, \%) & & & 0.895 \\
\hline 1 & $0(0 \%)$ & $1(0.8 \%)$ & \\
\hline$\|$ & $10(38.5 \%)$ & 46 (38.7\%) & \\
\hline III & $16(61.5 \%)$ & $72(60.5 \%)$ & \\
\hline $\operatorname{ECOG}(n, \%)$ & & & 0.003 \\
\hline 0 & $19(73.1 \%)$ & $112(94.1 \%)$ & \\
\hline 1 & $5(19.2 \%)$ & $6(5.0 \%)$ & \\
\hline 2 & $2(7.7 \%)$ & $1(0.8 \%)$ & \\
\hline Pathology (n, \%) & & & 0.036 \\
\hline Benign & $1(3.8 \%)$ & $9(7.6 \%)$ & \\
\hline Ampullary cancer & $13(50.0 \%)$ & $25(21.0 \%)$ & \\
\hline CBD cancer & $4(15.4 \%)$ & $17(19.3 \%)$ & \\
\hline PDAC & $5(19.2 \%)$ & 40 (42.0\%) & \\
\hline IPMN & $2(7.7 \%)$ & $3(2.5 \%)$ & \\
\hline PNET & $0(0 \%)$ & $6(5.0 \%)$ & \\
\hline Duodenal cancer & $1(3.8 \%)$ & $3(2.5 \%)$ & \\
\hline Tumor size (cm $\pm \mathrm{SD})$ & $2.68 \pm 1.80$ & $3.14 \pm 1.33$ & 0.231 \\
\hline $\begin{array}{l}\text { Lymph node harvest } \\
\text { (number } \pm S D \text { ) }\end{array}$ & $14.23 \pm 8.04$ & $19.83 \pm 9.71$ & 0.004 \\
\hline Pre-op bile drain (n, \%) & $14(53.8 \%)$ & $70(58.8 \%)$ & 0.400 \\
\hline $\begin{array}{l}\text { Abdominal surgery his- } \\
\text { tory }(n, \%)\end{array}$ & $5(19.2 \%)$ & $25(21.0 \%)$ & 0.539 \\
\hline Hypertension (n, \%) & $14(53.8 \%)$ & $50(42.0 \%)$ & 0.189 \\
\hline $\mathrm{DM}(\mathrm{n}, \%)$ & $8(30.8 \%)$ & $26(21.8 \%)$ & 0.232 \\
\hline CAD $(n, \%)$ & $1(3.8 \%)$ & $15(12.6)$ & 0.174 \\
\hline $\operatorname{COPD}(n, \%)$ & $1(3.8 \%)$ & $2(1.7 \%)$ & 0.450 \\
\hline CKD $(n, \%)$ & $1(3.8 \%)$ & $10(8.4 \%)$ & 0.378 \\
\hline $\mathrm{CCl}(\mathrm{n}, \%)$ & & & 0.062 \\
\hline 0 & $8(30.8 \%)$ & $63(52.9 \%)$ & \\
\hline 1 & $10(38.5 \%)$ & $36(30.3 \%)$ & \\
\hline 2 & $7(26.9)$ & $16(13.4 \%)$ & \\
\hline 3 & $0(0 \%)$ & $3(2.5 \%)$ & \\
\hline 4 & $0(0 \%)$ & $1(0.8)$ & \\
\hline 5 & 1 & $0(0 \%)$ & \\
\hline
\end{tabular}

Italic indicate statistic significance

MIPD minimal invasive pancreatoduodenectomy, OPD open pancreatoduodenectomy, ASA score American Society of Anesthesiologists classification score, ECOG Eastern Cooperative Oncology Group, CBD Common bile duct, $P D A C$ pancreatic ductal adenocarcinoma, IPMN intraductal papillary mucinous neoplasm, $P N E T$ pancreatic neuroendocrine tumor, DM Diabetes Mellitus, CKD chronic kidney disease, CCI Charlson comorbidity index

postoperative ICU stay, and re-admission rate. Despite the analysis did not achieve statistical significance, the pulmonary complications $(0 \%$ in the MIPD group vs. $17.6 \%$ in the OPD group, $\mathrm{P}=0.075)$ and mortality $(0 \%$ in the MIPD group vs. $11.8 \%$ in the OPD group, $\mathrm{P}=0.186$ ) tended to be more common in the OPD group.
Table 2 Overall short-term surgical outcomes

\begin{tabular}{llll}
\hline Variables & MIPD (N=26) & OPD (N=119) & P-value \\
\hline EBL (mL, IQR) & $300(87-562)$ & $300(150-400)$ & 0.981 \\
Operation time (min, IQR) & $540(420-662)$ & $462(370-596)$ & 0.011 \\
Conversion (n, \%) & $3(11.5 \%)$ & - & - \\
P duct size (mm \pm SD) & $3.27 \pm 1.41$ & $3.57 \pm 2.04$ & 0.958 \\
POHS (days, IQR) & $18(14-26)$ & $24(19-33)$ & 0.001 \\
Initiate oral diet (days, IQR) & $5(3-6)$ & $5(3-6)$ & 0.676 \\
Ambulation (days, IQR) & $6(4-7)$ & $6(4-7)$ & 0.815 \\
Drain removal (days, IQR) & $16(12-20)$ & $22(16-30)$ & $<0.001$ \\
ICU stay (days, IQR) & $3(2-6)$ & $3(2-6)$ & 0.743 \\
TPN dependence (days, IQR) & $7(5-11)$ & $8(6-12)$ & 0.184 \\
Major complication ( $\geq$ CD & $3(11.5 \%)$ & $27(22.7 \%)$ & 0.157 \\
Gr. 3) & & & \\
PPH (Grade B and C) & $2(7.7 \%)$ & $10(8.4 \%)$ & 0.633 \\
DGE (Grade B and C) & $2(7.7 \%)$ & $28(24.6 \%)$ & 0.071 \\
POPF (Grade B and C) & $2(7.7 \%)$ & $26(21.8 \%)$ & 0.077 \\
Pulmonary complication & $0(0 \%)$ & $10(8.4 \%)$ & 0.129 \\
IAI & $5(19.2 \%)$ & $40(33.6 \%)$ & 0.113 \\
30-day readmission & $1(3.8 \%)$ & $7(5.8 \%)$ & 0.865 \\
Mortality & $0(0 \%)$ & $6(5.0 \%)$ & 0.299 \\
\hline
\end{tabular}

Italic indicate statistic significance

EBL estimated blood loss, IQR interquartile range, SD standard deviation $P O H S$ post-operative hospital stay, ICU intensive care unit, TPN total parenteral nutrition, CD Gr. Clavien-Dindo grade, $P P H$ post-pancreatectomy hemorrhage, $D G E$ delayed gastric emptying, POPF post-operative pancreatic fistula, IAI intraabdominal infection

\section{Analysis of six surgical mortality cases in OPD group}

The details of six mortality cases in our study were revealed in Table 5 . All of our mortality cases were over 65-year-old. 3 patients was died of pulmonary complication (2 Nosocominal pneumonia and 1 aspiration pneumonia), 2 patients died of IAI with septic shock and 1 died of uncontrolled PPH. Relatively longer mean operation time (507.5 min), increased mean EBL $(591.6 \mathrm{~mL})$, high DGE rate, high POPF rate and late ambulation was also observed in these cases.

\section{Discussion}

In our retrospective study, we compared the postoperative outcomes between MIPD and OPD in elderly patients over 65 years of age. We also conducted a 1:2 PSM analysis to precisely evaluate the safety and efficacy of MIPD in elderly patients and minimize the nonrandomization bias in the results. Elderly patients who underwent MIPD had significantly shorter POHS, earlier drain removal and less DGE than those in the OPD group, the results of which were consistent before and after the PSM analysis. The time of initiation of oral diet, ICU stay, TPN dependence, and time taken for ambulation were comparable between the groups. Many recent 
Table 3 Baseline characteristics and pathological outcomes in elderly patients: PSM analysis

\begin{tabular}{|c|c|c|c|c|c|c|}
\hline \multirow[t]{2}{*}{ Variables } & \multicolumn{2}{|l|}{ Original cohort } & \multirow[t]{2}{*}{ P-value } & \multicolumn{2}{|l|}{ Matched cohort } & \multirow[t]{2}{*}{ P-value } \\
\hline & MIPD $(\mathrm{N}=20)$ & $\mathrm{OPD}(\mathrm{N}=66)$ & & MIPD $(\mathrm{N}=17)$ & $\mathrm{OPD}(\mathrm{N}=34)$ & \\
\hline Age (years) & $74.5 \pm 6.77$ & $72.48 \pm 5.35$ & 0.234 & $73.76 \pm 5.68$ & $73.70 \pm 6.82$ & 0.974 \\
\hline Male (Male) & $14(70.0 \%)$ & $40(60.6 \%)$ & 0.313 & $13(76.5 \%)$ & $25(73.5 \%)$ & 0.553 \\
\hline Malignancy $(\mathrm{n}, \%)$ & 19 (95\%) & 59 (84.9\%) & 0.402 & $16(94.1 \%)$ & 32 (94.1\%) & $>0.999$ \\
\hline $\mathrm{CCl}(\mathrm{n}, \%)$ & & & 0.211 & & & 0.558 \\
\hline 0 & $6(30.0 \%)$ & $28(42.4 \%)$ & & $6(35.3 \%)$ & $12(35.3 \%)$ & \\
\hline 1 & $6(30.0 \%)$ & $22(33.3 \%)$ & & $6(35.3 \%)$ & $12(35.3 \%)$ & \\
\hline 2 & 7 (35.0\%) & $12(18.2 \%)$ & & $4(23.5 \%)$ & $8(23.5 \%)$ & \\
\hline 3 & $0(0 \%)$ & $3(4.5 \%)$ & & $0(0 \%)$ & $2(5.9 \%)$ & \\
\hline 4 & $0(0 \%)$ & $1(1.5 \%)$ & & $0(0 \%)$ & $0(0 \%)$ & \\
\hline 5 & $1(5.0 \%)$ & $0(0 \%)$ & & 1 (5.9\%) & $0(0 \%)$ & \\
\hline ASA $(n, \%)$ & & & 0.388 & & & 0.463 \\
\hline I & $0(0 \%)$ & $0(0 \%)$ & & $0(0 \%)$ & $0(0 \%)$ & \\
\hline ॥ & $5(25.0 \%)$ & $21(31.8 \%)$ & & $4(23.5 \%)$ & 10 (29.4\%) & \\
\hline III & 15 (75.0\%) & 45 (68.2\%) & & $13(76.5 \%)$ & $24(70.6 \%)$ & \\
\hline Tumor type $(n, \%)$ & & & 0.402 & & & 0.583 \\
\hline Benign & $1(5.0 \%)$ & $6(9.1 \%)$ & & $1(3.8 \%)$ & $2(5.9 \%)$ & \\
\hline Ampullary cancer & $9(45.0 \%)$ & 16 (24.2\%) & & $7(41.2 \%)$ & 10 (29.4\%) & \\
\hline CBD cancer & 4 (20.0\%) & $11(16.7 \%)$ & & $3(17.6 \%)$ & $8(23.5 \%)$ & \\
\hline PDAC & $5(25.0 \%)$ & $26(39.4 \%)$ & & $5(29.4 \%)$ & $12(35.3 \%)$ & \\
\hline IPMN & $0(0 \%)$ & $3(4.5 \%)$ & & $0(0 \%)$ & $2(5.9 \%)$ & \\
\hline PNET & $0(0 \%)$ & $3(4.5 \%)$ & & $0(0 \%)$ & $0(0 \%)$ & \\
\hline Duodenal cancer & $1(5.0 \%)$ & $1(1.5 \%)$ & & $1(5.9 \%)$ & $0(0 \%)$ & \\
\hline ECOG $(n, \%)$ & & & 0.008 & & & 0.042 \\
\hline 0 & $13(65.0 \%)$ & $61(92.4 \%)$ & & $12(70.6 \%)$ & $32(94.1 \%)$ & \\
\hline 1 & $5(25.0 \%)$ & $4(6.1 \%)$ & & $3(17.6 \%)$ & $2(5.9 \%)$ & \\
\hline 2 & $2(10 \%)$ & $1(1.5 \%)$ & & $2(11.8 \%)$ & $0(0 \%)$ & \\
\hline Tumor size $(\mathrm{cm} \pm \mathrm{SD})$ & $2.98 \pm 1.93$ & $3.26 \pm 1.49$ & 0.562 & $2.8 . \pm 2.0$ & $2.92 \pm 1.25$ & 0.844 \\
\hline Lymph node harvest (number \pm SD) & $15.35 \pm 8.26$ & $19.42 \pm 9.88$ & 0.075 & $16.94 \pm 8.56$ & $17.44 \pm 7.77$ & 0.840 \\
\hline Pre-op bile drain $(n, \%)$ & $8(66.7 \%)$ & $39(59.1 \%)$ & 0.696 & $10(58.8 \%)$ & $21(61.8 \%)$ & 0.537 \\
\hline Abdominal surgery history $(\mathrm{n}, \%)$ & $4(20.0 \%)$ & $13(19.7 \%)$ & 0.601 & $3(17.6 \%)$ & $8(23.5 \%)$ & 0.462 \\
\hline
\end{tabular}

Italic indicate statistic significance

PSM propensity score matching, MIPD minimal invasive pancreatoduodenectomy, OPD open pancreatoduodenectomy, CCI Charlson comorbidity index, ASA score American Society of Anesthesiologists classification score, ECOG Eastern Cooperative Oncology Group

studies have reported that MIPD enabled early recovery, reduced postoperative pain and the need for analgesic injections and shortened the duration of POHS [28-30]. We also found MIPD is not commonly associated with delay gastric empty, which is a significant complication after OPD in elderly patients. Although the reason for the decreasing rate of delayed gastric emptying by MIPD is still under investigation, current studies had support that minimal invasive surgery with less tissue trauma might play a role [30, 31]. Despite of the reported benefit, MIPD did not completely mitigate the postoperative risk in elderly patients, and evidence regarding the benefits of the approach in this population remains limited. Our study confirmed the potential benefit of MIPD in improving recovery in elderly patients, without increasing the rate of perioperative complications and mortality.

$\mathrm{PD}$ is one of the most challenging surgeries owing to technique sensitivity, proximity of major vascular structures, and occurrence of various postoperative complications. Previous studies have reported that the 90-day mortality following PD in elderly patients may exceed $10 \%$, with the overall rate of morbidity ranging from 40 to $50 \%$ regardless of OPD or MIPD [32, 33]. In our series, there was no mortality in the MIPD group, and the rate of major complications was $15.0 \%$, which was notably lower than in the OPD group $(30.3 \%, \mathrm{P}=0.142)$ for elderly patients. We also observed that the MIPD group had fewer rates of pulmonary complications and 
Table 4 Short-term surgical outcomes in elderly patients: PSM analysis

\begin{tabular}{|c|c|c|c|c|c|c|}
\hline \multirow[t]{2}{*}{ Variables } & \multicolumn{2}{|l|}{ Original cohort } & \multirow[t]{2}{*}{ P-value } & \multicolumn{2}{|c|}{ Matched cohort } & \multirow[t]{2}{*}{ P-value } \\
\hline & $\operatorname{MIPD}(\mathrm{N}=20)$ & OPD $(N=66)$ & & MIPD $(N=17)$ & OPD $(N=34)$ & \\
\hline $\mathrm{EBL}(\mathrm{mL}, \mathrm{IQR})$ & $275(100-687)$ & $300(150-462)$ & 0.822 & $200(50-500)$ & $300(150-462)$ & 0.880 \\
\hline Operation time (min, IQR) & $525(414-640)$ & $467(377-604)$ & 0.161 & $420(410-526)$ & $456(360-604)$ & 0.181 \\
\hline$P$ duct size $(m m \pm S D)$ & $3.2 \pm 1.46$ & $3.6 \pm 1.87$ & 0.51 & $2.88 \pm 1.30$ & $3.66 \pm 1.69$ & 0.104 \\
\hline POHS (days, IQR) & $18(14-27)$ & $24(19-33)$ & 0.014 & $18(14-28)$ & $25(18-33)$ & 0.028 \\
\hline Initiate oral diet (days, IQR) & $5(3-7)$ & $5(4-6)$ & 0.946 & $5(3-7)$ & $5(4-6)$ & 0.992 \\
\hline Ambulation (days, IQR) & $7(5-8)$ & $6(5-9)$ & 0.922 & $7(5-8)$ & $6(5-10)$ & 0.739 \\
\hline Drain removal (days, IQR) & $16(13-20)$ & $22(17-27)$ & 0.004 & $16(13-20)$ & $21(17-27)$ & 0.012 \\
\hline ICU stay (days, IQR) & $4(3-6)$ & $4(3-7)$ & 0.909 & $4(3-6)$ & $4(3-7)$ & 0.840 \\
\hline TPN dependence (days, IQR) & $8(3-11)$ & $9(6-14)$ & 0.264 & $8(4-11)$ & $10(7-15)$ & 0.167 \\
\hline Major complication ( $\geq$ CD Gr. 3) & $3(15.0 \%)$ & $20(30.3 \%)$ & 0.142 & $3(17.6 \%)$ & $10(29.4 \%)$ & 0.290 \\
\hline PPH (Grade B and C) & $2(10.0 \%)$ & $8(12.1 \%)$ & 0.577 & $2(11.8 \%)$ & $3(8.8 \%)$ & 0.546 \\
\hline DGE (Grade B and C) & $2(10.0 \%)$ & $22(33.3 \%)$ & 0.042 & $1(5.9 \%)$ & $11(32.4 \%)$ & 0.036 \\
\hline POPF (Grade B and C) & $2(10.0 \%)$ & $14(21.2 \%)$ & 0.217 & $2(11.8 \%)$ & $8(23.5 \%)$ & 0.273 \\
\hline Pulmonary complication & $0(0 \%)$ & $10(15.2 \%)$ & 0.06 & $0(0 \%)$ & $6(17.6 \%)$ & 0.075 \\
\hline$|A|$ & $5(25.0 \%)$ & $19(28.8 \%)$ & 0.491 & $5(29.4 \%)$ & $11(32.4 \%)$ & 0.491 \\
\hline 30-day readmission & $1(5.0 \%)$ & $3(4.5 \%)$ & 0.856 & $1(5.9 \%)$ & $2(5.9 \%)$ & $>0.999$ \\
\hline Mortality & $0(0 \%)$ & $6(9.1 \%)$ & 0.193 & $0(0 \%)$ & $4(11.8 \%)$ & 0.186 \\
\hline
\end{tabular}

Italic indicate statistic significance

$E B L$ estimated blood loss, IQR interquartile range, SD standard deviation, $P O H S$ post-operative hospital stay, ICU intensive care unit, TPN total parenteral nutrition, $C D$ Gr. Clavien-Dindo grade, $P P H$ post-pancreatectomy hemorrhage, DGE delayed gastric emptying, $P O P F$ post-operative pancreatic fistula, IAI intraabdominal infection

Table 5 Analysis of six surgical mortality cases in OPD group

\begin{tabular}{|c|c|c|c|c|c|c|c|c|c|c|c|}
\hline Case & Age & Sex & Disease & $\mathrm{CCl}$ & ECOG & OPT (mins) & EBL $(m L)$ & DGE & $\begin{array}{l}\text { POPF } \\
\text { (Grade) }\end{array}$ & Amulation (day) & Cause of death \\
\hline 1 & $80-90$ & 1 & PDAC & 2 & 0 & 656 & 450 & None & 0 & None & Pneumonia \\
\hline 2 & $80-90$ & 1 & pNET & 2 & 0 & 562 & 400 & Yes & 0 & 10 & Pneumonia \\
\hline 3 & $80-90$ & 1 & CBD cancer & 1 & 0 & 340 & 250 & None & 3 & 6 & $\mathrm{PPH}$ \\
\hline 4 & $70-80$ & 1 & PDAC & 0 & 1 & 607 & 1000 & None & 0 & 4 & IAI with septic shock \\
\hline 5 & $70-80$ & 2 & Duodenum cancer & 2 & 2 & 270 & 350 & Yes & 3 & None & IAI with septic shock \\
\hline 6 & $80-90$ & 1 & Pancreatitis & 1 & 0 & 610 & 1100 & Yes & 0 & 10 & Pneumonia \\
\hline
\end{tabular}

OPD open pancreatoduodenectomy, PDAC pancreatic ductal adenocarcinoma, PNET pancreatic neuroendocrine tumor, CBD common bile duct, OPT operation time, $C C I$ Charlson comorbidity index, EBL estimated blood loss, ECOG Eastern Cooperative Oncology Group, DGE delayed gastric emptying, POPF post-operative pancreatic fistula, $P P H$ post-pancreatectomy hemorrhage, $I A I$ intraabdominal infection

post-pancreatectomy bleeding. The $\mathrm{P}$ value between the two groups was not significantly different, which might be due to the small sample size of the study. Among the six deaths in the OPD group, only one was due to POPF related hemorrhage. Other three deaths were due to postoperative pneumonia secondary to late ambulation or aspiration. Significantly less DEG rate in MIPD group might explain the lower risk of aspiration for elderly patients, which leading less pulmonary complication in our series. Although our data was inadequate to provide strong evidence regarding prevention of pulmonary complications by MIPD, several studies have reported that reducing postoperative pain by MIS may lead to decreased incidence of pneumonia [34, 35], which may explain the absence of mortality in the MIPD group.

Several studies have demonstrated that the risk of postoperative mortality and complications following MIPD may be higher in low volume centers $(\leq 22-25$ cases per year) [36, 37]. In our study, all MIPD was performed by at least two experienced hepato-pancreatico-biliary attending surgeon. We also decided to perform the surgery by the hybrid method to minimize the risk of POPF, which is the most common complication of PD. In instances of significant bleeding or requirement of vascular reconstruction during MIPD, early open conversion (11.1\%) was done. Notably, elderly patients in the MIPD group 
had significantly poor preoperative grade on ECOG scale; however, the surgical mortality and incidence of major complications were similar and even lower than in the OPD group. Our study proposed that MIPD is safe and feasible for elderly patients in low to moderate volume centers like our hospital through proper selection of candidates and by utilizing the hybrid method. The results of our study were comparable to those reported in the literature.

Several potential limitations of this study should be considered. Although we applied the PSM analysis to minimize the bias of the retrospective and non-randomized data, our study only considered short-term postoperative outcomes in a small cohort of elderly patients. Further large sample, prospective, and randomized controlled studies should be performed including long-term survival in order to confirm the results of the current study. Another limitation of the study is that our center started LPD in 2015, performing around 10-12 cases annually. Studies have reported that hepato-pancreatico-biliary surgeons might be required to perform more than 30 cases of LPD [38, 39] and 20 cases of RPD [40] to overcome the learning curve; therefore, the advantages of MIPD in elderly patients might be underestimated from our current data.

\section{Conclusion}

In conclusion, our study demonstrated that MIPD, compared to OPD, is a feasible and acceptable alternative for elderly patients with periampullary tumors. After counterbalancing the difference for patients and tumorrelated characteristics, MIPD still have some advantages over OPD such as shorter hospital stay, earlier drain removal and less DGE rate. The trend towards reduced pulmonary complication and mortality observed in our study might be confirmed in more precise randomized controlled studies.

\begin{abstract}
Abbreviations
PD: Pancreaticoduodenectomy; OPD: Open pancreaticoduodenectomy; MIS: Minimally invasive surgery; MIPD: Minimally invasive pancreaticoduodenectomy; LPD: Laparoscopic pancreaticoduodenectomy; RPD: Robotic pancreaticoduodenectomy; PSM: Propensity score-matching (PSM); ECOG: Eastern Cooperative Oncology Group; ASA: American Society of Anesthesiologists; CCl: Charlson comorbidity index; EBL: Estimated blood loss; POHS: Postoperative hospital stay; ICU: Intensive care unit; POPF: Postoperative pancreatic fistula; DGE: Delayed gastric emptying; PPH: Post-pancreatectomy hemorrhage; IQR: Interquartile rage; IAI: Intraabdominal infection.
\end{abstract}

\section{Acknowledgements}

We would like to extend our gratitude to the Biostatistics Center of Kaohsiung Chang Gung Memorial Hospital for their assistance with statistical analyses.

\section{Authors' contributions}

SMY, YYL and YWL conceived and designed the study. SMY, CCW, CCY and WFL made substantial contribution to data collection and analysis; SMY, YWL, and $\mathrm{CHY}$ participated in drafting the article; SMY, YYL and YWL revised the manuscript critically for important intellectual contents. SMY and YWL share the same contribution as the corresponding author for this manuscript. All authors read and approved the final manuscript.

Funding

The authors declare that they have no funding or financial ties to disclose.

Availability of data and materials

All data generated by and used in the study is available from the corresponding author upon reasonable request.

\section{Ethics approval and consent to participate}

The study was approved by the Chang Gung Medical Foundation Institutional Review Board (IRB), under authorization No. 202000247B0, and was conducted at Kaohsiung Chang Gang Memorial Hospital, Kaohsiung, Taiwan. The IRB approves the waiver of the participants' consent.

\section{Consent for publication}

Not applicable.

\section{Competing interests}

Drs. Shih-Min Yin, Yu-Yin Liu, Yueh-Wei Liu, Chee-Chien Yong, Chih-Chi Wang, Wei-Feng Li and Cheng-hsi Yeh have no conflicts of interest or financial ties to disclose. The abstract of this study had been accepted as the E-Poster of EAES 2020.

Received: 11 October 2020 Accepted: 6 January 2021

Published online: 25 January 2021

\section{References}

1. Crist DW, Sitzmann JV, Cameron JL. Improved hospital morbidity, mortality, and survival after the Whipple procedure. Ann Surg. 1987;206(3):35865. https://doi.org/10.1097/00000658-198709000-00014.

2. Winter JM, Cameron JL, Campbell KA, Arnold MA, Chang DC, Coleman J, Hodgin MB, Sauter PK, Hruban RH, Riall TS, Schulick RD, Choti MA, Lillemoe KD, Yeo CJ. 1423 pancreaticoduodenectomies for pancreatic cancer: a single-institution experience. J Gastrointest Surg. 2006;10(9):1199-210. https://doi.org/10.1016/j.gassur.2006.08.018 (discussion 1210-1191)

3. Ramai D, Ofosu A, Singh J, John F, Reddy M, Adler DG. Demographics, tumor characteristics, treatment, and clinical outcomes of patients with ampullary cancer: a surveillance, epidemiology, and end results (SEER) cohort study. Minerva Gastroenterol Dietol. 2019;65(2):85-90. https://doi. org/10.23736/S1121-421X.18.02543-6.

4. Rawla P, Sunkara T, Gaduputi V. Epidemiology of pancreatic cancer: global trends, etiology and risk factors. World J Oncol. 2019;10(1):10-27. https:// doi.org/10.14740/wjon1166.

5. Shore S, Vimalachandran D, Raraty MG, Ghaneh P. Cancer in the elderly: pancreatic cancer. Surg Oncol. 2004;13(4):201-10. https://doi. org/10.1016/j.suronc.2004.11.001.

6. Shi Y, Wang W, Qiu W, Zhao S, Wang J, Weng Y, Huo Z, Jin J, Wang Y, Deng $X$, Shen B, Peng $C$. Learning curve from 450 cases of robot-assisted pancreaticoduocectomy in a high-volume pancreatic center: optimization of operative procedure and a retrospective study. Ann Surg. 2019. https:// doi.org/10.1097/SLA.0000000000003664.

7. Pratt WB, Gangavati A, Agarwal K, Schreiber R, Lipsitz LA, Callery MP Vollmer CM Jr. Establishing standards of quality for elderly patients undergoing pancreatic resection. Arch Surg. 2009;144(10):950-6. https:// doi.org/10.1001/archsurg.2009.107.

8. Pedziwiatr M, Malczak P, Pisarska M, Major P, Wysocki M, Stefura T, Budzynski A. Minimally invasive versus open pancreatoduodenectomy-systematic review and meta-analysis. Langenbecks Arch Surg. 2017;402(5):84151. https://doi.org/10.1007/s00423-017-1583-8.

9. Ito Y, Kenmochi T, Irino T, Egawa T, Hayashi S, Nagashima A, Kitagawa Y. The impact of surgical outcome after pancreaticoduodenectomy in elderly patients. World J Surg Oncol. 2011;9:102. https://doi org/10.1186/1477-7819-9-102.

10. Coolsen MM, Bakens M, van Dam RM, Olde Damink SW, Dejong $\mathrm{CH}$. Implementing an enhanced recovery program after 
pancreaticoduodenectomy in elderly patients: is it feasible? World J Surg. 2015;39(1):251-8. https://doi.org/10.1007/s00268-014-2782-x.

11. Chen YT, Ma FH, Wang CF, Zhao DB, Zhang YW, Tian YT. Elderly patients had more severe postoperative complications after pancreatic resection: a retrospective analysis of 727 patients. World J Gastroenterol. 2018;24(7):844-51. https://doi.org/10.3748/wjg.v24.17.844.

12. Futagawa Y, Kanehira M, Furukawa K, Kitamura H, Yoshida S, Usuba T, Misawa T, Ishida Y, Okamoto T, Yanaga K. Study on the validity of pancreaticoduodenectomy in the elderly. Anticancer Res. 2017;37(9):5309-16. https://doi.org/10.21873/anticanres.11957.

13. Shaib WL, Zakka K, Hoodbhoy FN, Belalcazar A, Kim S, Cardona K, Russell MC, Maithel SK, Sarmiento JM, Wu C, Akce M, Alese OB, El-Rayes BF. In-hospital 30-day mortality for older patients with pancreatic cancer undergoing pancreaticoduodenectomy. J Geriatr Oncol. 2019. https:// doi.org/10.1016/j.jgo.2019.10.012.

14. Zong L, Wu A, Wang W, Deng J, Aikou S, Yamashita H, Maeda M, Abe M, Yu D, Jiang Z, Seto Y, Ji J. Feasibility of laparoscopic gastrectomy for elderly gastric cancer patients: meta-analysis of non-randomized controlled studies. Oncotarget. 2017;8(31):51878-87. https://doi.org/10.18632/oncot arget.16691.

15. Antoniou SA, Antoniou GA, Koch OO, Pointner R, Granderath FA. Laparoscopic colorectal surgery confers lower mortality in the elderly: a systematic review and meta-analysis of 66,483 patients. Surg Endosc. 2015;29(2):322-33. https://doi.org/10.1007/s00464-014-3672-x.

16. Yan $Q, X u L B$, Ren ZF, Liu C. Robotic versus open pancreaticoduodenectomy: a meta-analysis of short-term outcomes. Surg Endosc. 2019. https ://doi.org/10.1007/s00464-019-07084-3.

17. Han SH, Kang CM, Hwang HK, Yoon DS, Lee WJ. The Yonsei experience of 104 laparoscopic pancreaticoduodenectomies: a propensity scorematched analysis with open pancreaticoduodenectomy. Surg Endosc. 2019. https://doi.org/10.1007/s00464-019-06942-4

18. Chen XM, Sun DL, Zhang Y. Laparoscopic versus open pancreaticoduodenectomy combined with uncinated process approach: a comparative study evaluating perioperative outcomes (Retrospective cohort study). Int J Surg. 2018;51:170-3. https://doi.org/10.1016/j.ijsu.2018.01.038.

19. Nickel F, Haney CM, Kowalewski KF, Probst P, Limen EF, Kalkum E, Diener MK, Strobel O, Muller-Stich BP, Hackert T. Laparoscopic versus open pancreaticoduodenectomy: a systematic review and meta-analysis of randomized controlled trials. Ann Surg. 2020;271(1):54-66. https://doi. org/10.1097/SLA.0000000000003309.

20. van Hilst J, de Rooij T, Bosscha K, Brinkman DJ, van Dieren S, Dijkgraaf MG, Gerhards MF, de Hingh IH, Karsten TM, Lips DJ, Luyer MD, Busch OR, Festen S, Besselink MG, Dutch Pancreatic Cancer G. Laparoscopic versus open pancreatoduodenectomy for pancreatic or periampullary tumours (LEOPARD-2): a multicentre, patient-blinded, randomised controlled phase 2/3 trial. Lancet Gastroenterol Hepatol. 2019;4(3):199-207. https:// doi.org/10.1016/S2468-1253(19)30004-4.

21. Mauriello C, Polistena A, Gambardella C, Tartaglia E, Orditura M, De Vita F, Santini L, Avenia N, Conzo G. Pancreatic stump closure after pancreatoduodenectomy in elderly patients: a retrospective clinical study. Aging Clin Exp Res. 2017;29(Suppl 1):35-40. https://doi.org/10.1007/s4052 0-016-0657-8.

22. Kow AW, Sadayan NA, Ernest A, Wang B, Chan CY, Ho CK, Liau KH. Is pancreaticoduodenectomy justified in elderly patients? Surgeon. 2012;10(3):128-36. https://doi.org/10.1016/j.surge.2011.02.005.

23. Charlson ME, Charlson RE, Peterson JC, Marinopoulos SS, Briggs WM, Hollenberg JP. The Charlson comorbidity index is adapted to predict costs of chronic disease in primary care patients. J Clin Epidemiol. 2008;61(12):1234-40. https://doi.org/10.1016/j.jclinepi.2008.01.006.

24. Bassi C, Marchegiani G, Dervenis C, Sarr M, Abu Hilal M, Adham M, Allen P, Andersson R, Asbun HJ, Besselink MG, Conlon K, Del Chiaro M, Falconi M, Fernandez-Cruz L, Fernandez-Del Castillo C, Fingerhut A, Friess H, Gouma DJ, Hackert T, Izbicki J, Lillemoe KD, Neoptolemos JP, Olah A, Schulick R, Shrikhande SV, Takada T, Takaori K, Traverso W, Vollmer CR, Wolfgang CL, Yeo CJ, Salvia R, Buchler M, International Study Group on Pancreatic S. The 2016 update of the International Study Group (ISGPS) definition and grading of postoperative pancreatic fistula: 11 years after. Surgery. 2017;161(3):584-91. https://doi.org/10.1016/j.surg.2016.11.014.

25. Wente MN, Bassi C, Dervenis C, Fingerhut A, Gouma DJ, Izbicki JR, Neoptolemos JP, Padbury RT, Sarr MG, Traverso LW, Yeo CJ, Buchler MW. Delayed gastric emptying (DGE) after pancreatic surgery: a suggested definition by the International Study Group of Pancreatic Surgery (ISGPS). Surgery. 2007;142(5):761-8. https://doi.org/10.1016/j.surg.2007.05.005.

26. Wente MN, Veit JA, Bassi C, Dervenis C, Fingerhut A, Gouma DJ, Izbicki JR, Neoptolemos JP, Padbury RT, Sarr MG, Yeo CJ, Buchler MW. Postpancreatectomy hemorrhage (PPH): an International Study Group of Pancreatic Surgery (ISGPS) definition. Surgery. 2007;142(1):20-5. https://doi. org/10.1016/j.surg.2007.02.001.

27. Dindo D, Demartines N, Clavien PA. Classification of surgical complications: a new proposal with evaluation in a cohort of 6336 patients and results of a survey. Ann Surg. 2004;240(2):205-13. https://doi. org/10.1097/01.sla.0000133083.54934.ae.

28. Langan RC, Graham JA, Chin AB, Rubinstein AJ, Oza K, Nusbaum JA, Smirniotopoulos J, Kayser R, Jha R, Haddad N, Al-Kawas F, Carroll J, Hanna J, Parker A, Al-Refaie WB, Johnson LB. Laparoscopic-assisted versus open pancreaticoduodenectomy: early favorable physical quality-of-life measures. Surgery. 2014;156(2):379-84. https://doi.org/10.1016/j.surg.2014.03.018.

29. Sharpe SM, Talamonti MS, Wang CE, Prinz RA, Roggin KK, Bentrem DJ, Winchester DJ, Marsh RD, Stocker SJ, Baker MS. Early national experience with laparoscopic pancreaticoduodenectomy for ductal adenocarcinoma: a comparison of laparoscopic pancreaticoduodenectomy and open pancreaticoduodenectomy from the National Cancer Data Base. J Am Coll Surg. 2015;221(1):175-84. https://doi.org/10.1016/j.jamcollsurg.2015.04.021.

30. Zhao Z, Yin Z, Hang Z, Ji G, Feng Q, Zhao Q. A systemic review and an updated meta-analysis: minimally invasive vs open pancreaticoduodenectomy. Sci Rep. 2017;7(1):2220. https://doi.org/10.1038/s41598-017-02488-4.

31. Wang SE, Shyr BU, Chen SC, Shyr YM. Comparison between robotic and open pancreaticoduodenectomy with modified Blumgart pancreaticojejunostomy: a propensity score-matched study. Surgery. 2018;164(6):1162-7. https://doi.org/10.1016/j.surg.2018.06.031.

32. Chapman BC, Gajdos C, Hosokawa P, Henderson W, Paniccia A, Overbey DM, Gleisner A, Schulick RD, McCarter MD, Edil BH. Comparison of laparoscopic to open pancreaticoduodenectomy in elderly patients with pancreatic adenocarcinoma. Surg Endosc. 2018;32(5):2239-48. https:// doi.org/10.1007/s00464-017-5915-0.

33. Liang Y, Zhao L, Jiang C, Hu P, Wang H, Cai Z, Wang W. Laparoscopic pancreaticoduodenectomy in elderly patients. Surg Endosc. 2019. https://doi. org/10.1007/s00464-019-06982-w.

34. Fujita T, Sakurai K. Multivariate analysis of risk factors for postoperative pneumonia. Am J Surg. 1995;169(3):304-7. https://doi.org/10.1016/S0002 -9610(99)80163-9.

35. Bablekos GD, Roussou T, Rasmussen T, Vassiliou MP, Behrakis PK. Postoperative changes on pulmonary function after laparoscopic and open cholecystectomy. Hepatogastroenterology. 2003;50(53):1193-200.

36. Kutlu OC, Lee JE, Katz MH, Tzeng CD, Wolff RA, Varadhachary GR, Vauthey JN, Fleming JB, Conrad C. Open pancreaticoduodenectomy case volume predicts outcome of laparoscopic approach: a population-based analysis. Ann Surg. 2018;267(3):552-60. https://doi.org/10.1097/SLA.0000000000002111.

37. Adam MA, Thomas S, Youngwirth L, Pappas T, Roman SA, Sosa JA. Defining a hospital volume threshold for minimally invasive pancreaticoduodenectomy in the United States. JAMA Surg. 2017;152(4):336-42. https:// doi.org/10.1001/jamasurg.2016.4753.

38. Nagakawa Y, Nakamura Y, Honda G, Gotoh Y, Ohtsuka T, Ban D, Nakata K, Sahara Y, Velasquez V, Takaori K, Misawa T, Kuroki T, Kawai M, Morikawa T, Yamaue H, Tanabe M, Mou Y, Lee WJ, Shrikhande SV, Conrad C, Han HS, Tang CN, Palanivelu C, Kooby DA, Asbun HJ, Wakabayashi G, Tsuchida A, Takada T, Yamamoto M, Nakamura M. Learning curve and surgical factors influencing the surgical outcomes during the initial experience with laparoscopic pancreaticoduodenectomy. J Hepatobiliary Pancreat Sci. 2018;25(11):498-507. https://doi.org/10.1002/jhbp.586.

39. Wang M, Meng L, Cai Y, Li Y, Wang X, Zhang Z, Peng B. Learning curve for laparoscopic pancreaticoduodenectomy: a CUSUM analysis. J Gastrointest Surg. 2016;20(5):924-35. https://doi.org/10.1007/s1 1605-016-3105-3.

40. Shyr BU, Chen SC, Shyr YM, Wang SE. Learning curves for robotic pancreatic surgery-from distal pancreatectomy to pancreaticoduodenectomy. Medicine (Baltimore). 2018;97(45):e13000. https://doi.org/10.1097/ MD.0000000000013000.

\section{Publisher's Note}

Springer Nature remains neutral with regard to jurisdictional claims in published maps and institutional affiliations. 